\title{
Developing a benchmarking approach to evaluate the state of warranty in automakers: A case study of two biggest automakers in Middle East
}

\author{
Mahdi Kheyrkhahan $^{\mathrm{a}^{*}}$, Hamid kalaei ${ }^{\mathrm{b}}$, Hamidreza Karkehabadi ${ }^{\mathrm{c}}$ and Batool Bozorgmehr ${ }^{\mathrm{d}}$
}

${ }^{a}$ Payame Noor University, Instructor, Management Group,Garmsar, Semnan, Iran

${ }^{b}$ Gharbsteel Center Of Uast, Instructor, Accounting Group, Mahdishahr, Semnan, Iran

'Semnan University of Applied Science and Technology, Instructor, Palande Sof Center, Semnan, Iran

${ }^{d}$ Gharbsteel Center Of Uast, Instructor, Accounting Group, Mahdishahr, Semnan, Iran

\begin{tabular}{|c|c|}
\hline A R T I C L E I N F O & A B S T RACT \\
\hline $\begin{array}{l}\text { Article history: } \\
\text { Received June 28, } 2012 \\
\text { Received in Revised form } \\
\text { August, 26, } 2012 \\
\text { Accepted 29 August } 2012 \\
\text { Available online } \\
\text { 8 September } 2012 \\
\text { Keywords: } \\
\text { Fuzzy AHP } \\
\text { Product warranty } \\
\text { After sale services } \\
\text { Quality }\end{array}$ & $\begin{array}{l}\text { Warranty is recognized as an important component of product marketing and it can increase } \\
\text { customers' confidence. All services during warranty are considered as an additional cost for } \\
\text { producers where these expenses are associated with product reliability and warranty } \\
\text { components. Product reliability is also influenced by decisions taken in the field of product } \\
\text { design and process and arrangement in this period. Product reliability also plays an important } \\
\text { role in new products for production planning. As competition increases all around the world, } \\
\text { there is an increasing interest in providing suitable substrates for the acceleration of economic } \\
\text { growth and development and production. Warranty is one of the basic infrastructures and } \\
\text { behaviors in today's competitive world, which is boosting sales and typically profits and } \\
\text { customer's satisfaction and confidence play important roles in achieving this goal. In this study, } \\
\text { we first evaluate warranty policies and strategies and then we consider after selling services } \\
\text { taken in a case study. Finally, some strategies are introduced to improve the current situation } \\
\text { and to achieve suitable model for ideal situation. }\end{array}$ \\
\hline
\end{tabular}

\section{Introduction}

Today, after sales service issues have been raised as important features for product sales. Generally, warranty is essential for products, which requires the manufacturer to compensate losses for the customer (buyer) due to conditions of warranty when the warranty products, despite their expected functions, are broken or damaged (Wang \& Pham, 2006). Setting any kind of warranty, which includes some support services for the product will create additional expenditures for manufacturers. These costs are unpredictable, but generally are in the range of $2 \%$ to $15 \%$ of net sales (McGuire, 1980). Products warranty includes a series of producer's marketing strategies and sellers (Murthy \&

* Corresponding author.

E-mail addresses: m.kh5155@yahoo.com (M. Kheyrkhahan) 
Jackn, 2003). Many manufacturers believe warranty increases customer draws, indicates the product reliability and indicates the product differences compared with other competitors' products (Murthy \& Djamaludin, 2002). On one hand, warranty creates a significant impact on operational costs by the manufacturer and on the other hand with increasing customer confidence, increases product sales. As a result, warranty plays an important role in exchanges between buyer and supplier (Minjae \& Pham, 2010). Mitra and Jayprakash (1990) presented a multi-objective model for warranty estimation.

Organizations loose an annual average of 10 to 30 percent of their customers and managers often do not know the reasons and consequences. According to a survey held among marketing and sales managers of 350 different firms in 1999, approximately 48\% of executive marketing managers and 30 percent of the sales managers did not know anything about reasons behind losses. While many studies show that keeping current customers is usually less costly than finding a new customer. A loyal customer normally creates more income over the years of his/her relationships with the company, especially if a customer is encouraged to receive high quality services promised for. Therefore, interacting with existing customers is much less costly than searching for new customers.

Customers are deserved to get what they are promised to, companies can attract customers when they timely act to their promises. In decision making for purchasing a commodity, the buyer can compare the product in terms of all aspects compared with other similar products. Whenever there are two products with similar characteristics, it would be extremely difficult to decide and people make their selection based on inherent characteristics of product such as price, features, quality, reliability, etc. This time, after-sales services including warranty, availability of parts and cost, service and maintenance play important roles to select or ignore the product. Therefore, in product purchase, warranty is a known issue for customers. When, it goes to a new product, most customers are not sure about its performance. Here warranty plays a major role in increasing customer confidence in buying the product and depending on the product and the buyer; warranty shall be set for various types (Murthy \& Djamaludin, 2002). For this reason, this study presents a comparative approach to assess the existing guarantee situation in Iran in comparison with some selected countries.

\section{Statement of the Problem}

Warranty in addition to executives and industry owners, is an important issue for regulatory department and customers where they are interested in using the services of these firms. Many managers attempt to achieve higher levels of efficiency and activities close to the border of productive surface and selection of an appropriate scale for their economic activities and increase their abilities to compete with competitors to achieve maximum performance levels. In addition, regulatory agencies and the public customers enjoy the services of these institutions because of the services reduce total price and mediated costs and increase quality due to increase in performance in system analysis. Today the real missions of these organizations are to understand customers' needs and demands and to provide solutions for more customer satisfaction. Being excellence in market is obtained only by providing customer satisfaction, innovation and superior quality services. Customer satisfaction is the fundamental objectives of any organization.

Satisfied customers are the key to success. In helping to achieve organizational goals, customer satisfaction levels should be increased. Warranty is a kind of protection of customers and producers, representing product quality and an important component of market strategy and increase customer confidence in purchasing a product, which has not ever been consumed. All of this led to the thinking of legislators to pass laws to regulate the warranty period, For example, the Europe Union (EU) passed legislation on a 2-year warranty for all products (Blischke \& Murthy, 1992; Christozov et al., 2009). Polatoglu and Sahin (1998) in comprehensive study proposed some theory and methodology for probability distributions of cost, revenue and profit over a warranty cycle. Iskandar and Murthy (2009) proposed another repair-replace strategy based on usage rate for items sold with a two- 
dimensional warranty. Mitra and Jayprakash (1997) studied market share and warranty costs for renewable warranty programs.

\section{Literature review}

Due to the diversity goals, the product warranty has attracted many researchers in various aspects. To examine a warranty, the following aspects are examined:

- History: The originality of warranty,

- Legal: The court complaints, product responsibility,

- Legislation: Federal Trade Commission (FTC), the latest relevant legislation in the United States and Europe Union (EU),

- Economic: market equilibrium, social welfare,

- Behavioral: buyer reaction, influence on decisions to purchase, consider the warranty, the plaintiff's behavior,

- Customer: product information, customer support,

- Engineering: design, manufacturing, quality control, testing,

- Statistical results: data analysis, the reliability analysis,

- Operations research: modeling costs, process optimization,

- Accounting: Tracking the costs,

- Marketing: Assessing the client thinking, assessment sales centers, use warranty as a marketing tool, warranty impact on sales,

- Management: determining warranty policies, decisions about giving the warranty service,

- Social: categories and social policies.

An effective warranty policy indicates high products reliability and attracts customer's assurance (Murthy et al., 2004). A producer adopts various types of warranty policies in order to reap more profits to the clients (Blischke, 1990; Glickman \& Berger, 1976) and many studies focus on product reliability. As discussed by Wiener (1985), there is an unbalance demand when a manufacturer produces high quality and low cost benefits and a producer offers the same low quality product. This means that only high quality product manufacturers attempt to provide long-term warranty and lowquality producers cannot offer long-term warranty because they do not have the capability to offset losses caused by failures of continuous product or services. In other words, when the producers of high quality products reduce their expenditures warranty will not mean as an indication of the reliability (Chukova et al., 1993; Thomas \& Rao, 1999; Wu et al., 2006). This is called the stretch balance where manufacturing enterprises of the high and lower quality producers, both recognize warranty as a sign of product reliability.

Another way to look for a warranty as a sign of reliability was introduced by Beales (1981) and Weiner (1985) proposed a name of "the hidden profits" and relies on this topic, where customers cannot understand reliability of products with a simple inspection. The issue of hidden profits means that warranty is an important aspect of a product, which could reach to an important point but hidden. According to Agrawal (1996), "Customers believe that the warranty as a suitable signal of product reliability". Blischke and Murthy (1992) published the first article in this issue of mathematical modeling for cost of warranty period. They presented a comprehensive classification for all types of warranty for new products (Blischke \& Murthy, 1992). 


\section{Methodology of the study}

Since this case study also emerged in firms and experts, review and decision making are regarded as selection of indicators. Then, using the interview questionnaire, the necessary data on the specific attributes are collected. The data should be standardized so that it could easily be assessed, analyzed and summarized. Studies based on this method takes place in different organizations by people and this is one of excellence of this study in organizational studies. The method tries to give a real and regular view of the under study phenomenon to researchers. The numbers of experts who have been available are 50 people. In modern management literature, each of the traditional functions of management such as planning, organizing, controlling effects a decision. Many decisions in today's world are more complex than they were in previous years. On the other hand, many factors are in the realm of social qualitative issues and cannot precisely recognize the dimensions of these issues and make their priorities quantitatively in shaping and influencing the issues. Therefore, the computational processes required to be analytic. One of the most important processes is analytical hierarchy process (AHP). The process uses pare-wise comparisons and then for evaluating various factors, the coefficients are calculated.

Steps in this article, after a general presentation of the research are as follows:

1. First, the existing conditions analysis and the indicators to identify draw firm priorities and hierarchical structures are specified.

2. Information gathered through talking with experts and specialists as well as individuals informed and involved in system, and use of resources such as scientific articles, books and Internet.

3. Formation of pare-wise comparisons matrices for different levels using fuzzy AHP technique and obtaining the final weights are taken in this step.

4. Finally, the results of research and improvement strategies are offered.

\section{1 fuzzy AHP technique}

Accessing to knowledge without ambiguity in today's world is almost impossible. Since the introduction of two-valued logic of Aristotle, we have been able to achieve significant successes to handle some express some uncertainties. Technology is growing increasingly more efficient. Fuzzy logic is an alternative strategy for handling uncertainties in our world and the proposed study of this paper uses Fuzzy logic to handle uncertainty. There are several studies associated with the implementation of fuzzy techniques. Wang et al. (2007), for instance, proposed a method for selection of optimum maintenance strategies based on a fuzzy analytic hierarchy process. Park and Pham (2010) presented an altered quasi-renewal concepts for modeling renewable warranty costs with imperfect repairs.

\section{Case study and analyzing the suggested method}

Four manufacturing firms surveyed in this article are:

\subsection{Iran Khodro industrial groups}

Iran Khodro Company is one of the largest automakers in Middle East. Iran Khodro produced 542 thousand vehicles in 2006 and broke the record for production cars and commercial vehicles in the car with a 54 percent market share. Also in line with standards of ISO 9000, received ISO 9001 certification from the German Institute RWTUV and many certifications in the health, safety and the environment were included in ISO 14001 and OHSAS18001. Based on the evaluation results of this organization, warranty status indicators in the first half of 2007 showed that the growth of car service 
status in the second half of 2006 was equivalent to 3\%. ISACO Company, Iran Khodro's products warranty provider, in the last assessment conducted by the Iranian Standard and Quality Inspection, which was the first six months of 2007. Iran Khodro warranty of network benefits can be pointed to the following,

- Network standard warranty,

- special workshop tools,

- Electronic diagnostic devices,

- $\quad$ Technical and trained personnel,

\subsection{Saipa Company}

SAIPA Company incorporates more than 80 affiliated companies directly and indirectly and has become a large automaker group with different types of vehicles possible to produce. In the third round of the Standard \& Quality Inspection, SAIPA won the first rank among all automotive manufacturers and importers. In the third round of evaluation of SAIPA car manufacturing company that belongs to the first 6 months in the early of 2008 has been able to gain the first rank with 655 points.

\subsection{Hyundai Company}

Hyundai refers to a collection of factories and related organizations by Joe Chung - Jung of South Korea. The first Hyundai Company was founded in $1947 \mathrm{AD}$ as a construction company and eventually Hyundai of South Korea became the largest chain company in its region.

\subsection{Toyota Company}

Toyota is a symbol of strong development of a company, from the family business into a truly global company. Toyota is a symbol of successful management that has to offer many innovative and creative ideas such as symmetry of (5S), continuous improvement (Kaizen), Kanban systems, lean manufacturing and JIT system to the world.

\subsection{Comparison criteria}

For choosing and evaluating the best firm, we must first set enterprise goals as compared criteria. Different firms may have various objectives and criteria, which are generally classified as much as they can be laid to rest:

\subsection{1 cost}

Today, sales service issues are considered as important features in the product sales. Setting any kind of warranty, which includes some support services for the product, will cause additional costs for manufacturers. These costs are unpredictable, but generally contain 2 to 15 percent of net sales. On one hand, warranty will have a significant impact on operational costs by the manufacturer and on the other hand, with increasing customer confidence, it can increase sales of products. As a result, warranty plays a very important role in the transactions between buyer and supplier (Murthy \& Djamaludin, 2002). These days, products are more complex and it becomes harder for customers to choose their desired products. Warranty is used as a sign of the function and product reliability. Consequently, with respect to both product performance and also the type of warranty offered to the customer, manufacturer costs will change, which means whenever the warranty period is set longer; 
the cost will be producing more (Scitovszky, 1945). Warranty costs can generally be classified as follows:

\subsubsection{Operating and performance costs}

These costs are associated with implementation of effective and efficient execution of a warranty on certain products in a manufacturing firm by achieving this issue requires the use of time and expertise to design and to perform warranty and surveying its efficiency. When a buyer has different options to choose product warranty, costs will also change proportion to the type of services (Murthy \& Djamaludin, 2002).

\subsubsection{Supporting and supplying costs}

Logistic supports manufacturing, materials, transportation and warehousing and distribution items as well as infrastructure supports for different activities during the product life of a product. Supply chain logistics are necessary requirements to transport raw materials and components from suppliers to manufacturing plants and final product transport from factory to the retail market through warehouse and retail store systems.

\subsubsection{Agencies costs}

Many manufacturers employ independent service representatives to perform warranty service for an appropriate contract, which result in mutual benefit of both customers and producers. Manufacturer can provide proper incentives service for representatives and provide one service contract for a representative of a good incentive for further efforts. Monitoring activities can be represented by the manufacturer to obtain new information. Such information helps manufacturers identify required warranty services performed by a representative. However, these issues have resulted in additional labor costs and production (Murthy et al., 2004).

\subsubsection{Market}

Product warranty is part of the marketing strategies for manufacturers and retailers (Thomas \& Maronick, 2006).The process of a customer purchasing including durable goods, industrial and commercial ones is a multi-stage process, which includes the following,

- The need for a product shaped,

- The necessary information from different available brands,

- evaluate Brands and decisions based on price, performance and after sales service,

- Final purchase.

To help this process, manufacturers must upgrade their brand and provide information to help customers in their decision-making process (Murthy \& Djamaludin, 2002).

\subsubsection{1 selling rate}

Skills to attract customers and create integrity between client and firm have significant impacts on profitability. To increase customers' willingness to purchase goods, producers must determine reasonable price for their products. It should be noted that the sale price is only a foreign element and direct in dealing with customers. For example, for the same products, although offering the product with a lower price leads to sales growth, but on the other profit per unit of goods will also decrease (Thomas \& Maronick, 2006). 


\subsubsection{Price}

One of the most effective components in market is the product price with warranty. Any reduction in warranty costs can offer the product with good price and be competitive with similar products. In calculating the selling price of a product with warranty, costs for support should also be considered.

\subsubsection{Advertisement and ability to attract customer}

Warranty as an approaching tool has many features and one of the most important one is to provide the assured product for the buyer. Warranty policies as a selling tool depends on whether a supplier tries to promote a product or only looks for promotional aspect of it. If only the advertising aspect of warranty becomes important, looking at warranty is to keep profits just because some manufacturers want a warranty to hide their quality of products behind it (Murthy et al., 2004).

\subsubsection{Profit}

It is obvious that each firm tries to achieve more profit, and this is possible by adopting market-based policies. Many customers look for the price of goods as a sign of product quality and this is because consumers believe that products with higher quality maintain higher costs for producers and, surely, higher product prices also go while pricing may be in order to higher profit. Meanwhile, the prices should not be in the extent to discourage customers from purchasing products. Therefore, manufacturers should pay more attention to price as a competitive tool in the market. Another important factor that can encourage customers to buy the product is product quality. However, quality cannot be found on the product design (Ives \&Vitale, 1988).

\subsubsection{Risk}

The product warranty as a risk sharing mechanism is effective on two aspects of commercial transactions: first the legal context in the development of trade and second increases openness between the parties. Two sources of risk to be covered, in the first one, a purchased product must be replaced when customer realize that it is damaged before purchase occurs and the second one is when a purchased product can be returned when customer is not satisfied with the features (Murthy\&et. al.,2004).

\subsubsection{Risk due to incorrect information}

If the transmitter and receiver in the communication process, have different backgrounds and skills, and naturally use different languages or different process of information, they occur when information asymmetry happens in the relationship between them. One of the major problems in determining the risk of incorrect information is personal and private risk. For example, the message includes information about an individual product, reaches the wrong information to mislead the other mentors and customers.

This incorrect information may have different degrees and results for a group of clients. So from one perspective to assess the risk of information asymmetry in one group of clients, need to consider each individual reaction to false information and group risk is a combination of the individual reactions. In other words, group classification into subgroups and risk monitoring at the level of risk subgroups provides additional insight. Some products may represent a characteristic or feature of the product to several customers as well as the ability to perform a specific task or group of functions in the right information, however, can give false product information about other features and functions. 


\subsubsection{2 product malfunctioning risk}

Warranty is a contract that is committed to help seller or manufacturer support their products, and a contract about product performance and commitment of seller. Warranty is used when there is a real problem in damaged product. Warranty is a specific contract between the provider and the purchaser on repairing or replacing the defective component or refund the whole or part of price because of the problem occurred.

Warranty is a tool for reducing customers' risk. Product warranty is a way to reduce customers risk against the probable payment costs for repairing the failures when product performance is not expected. Furthermore, the warranty used to be an effective method for reducing the risk of new products and products with sophisticated technologies and for the early period of products life where customer experience is less about them (Thomas \& Maronick, 2006).

\subsubsection{Performance risk}

Usually sellers do not have information about customer's real requirements and these causes customer to make wrong shopping in some cases. Besides, the service does not have enough performance and this could damage the reputation of the service provider. Additionally, legitimate and effective source of product supply can be determined by differently and the distance is important for the buyers. Distance not only depends on access, choice, freedom to choose and the buyer's affordability, but also the time, which is more important factor. Reputation and brand strength, the ability to repeat purchases, the buying and the shelves are also efficient. Overall efficiency occurs when the purchasers have overall availability to the supplier in accordance with their expectation (Murthy et al., 2004).

\subsubsection{Notion}

Warranty is as an integral part of the trade and exchanges among various countries. People in different countries have various perceptions on warranty characteristics in terms of social, legislation, etc. Warranty assures customers that if product ruined it can be repaired or be replaced with no cost or little cost. Another aspect is the role of informing and publicity. Because most customers would infer that buying a product with a long warranty period is safer than buying a product with shorter period of warranty. One of the principal roles of warranty from the manufacturer's point of view is its supportive aspect whatever the warranty covers only a limited period and only according to circumstances.

Manufacturer may provide the support of future product by maintenance services. The second important warranty goal for manufacturer is to develop different features such as offering a product with a long warranty period, offering a product with a short warranty period and this could be an effective tool for product development. This is especially important when a new product market does not have a steady state. Studies show that the warranties can serve significant impact on the customer's product selection and customers willing to pay more money for products with warranty (Thomas \& Maronick, 2006).

Consider four manufacturing firms. According to the criteria and according to a numeric data collection, comparisons judgment matrix was prepared in which comparisons are shown as a triangular fuzzy number. 


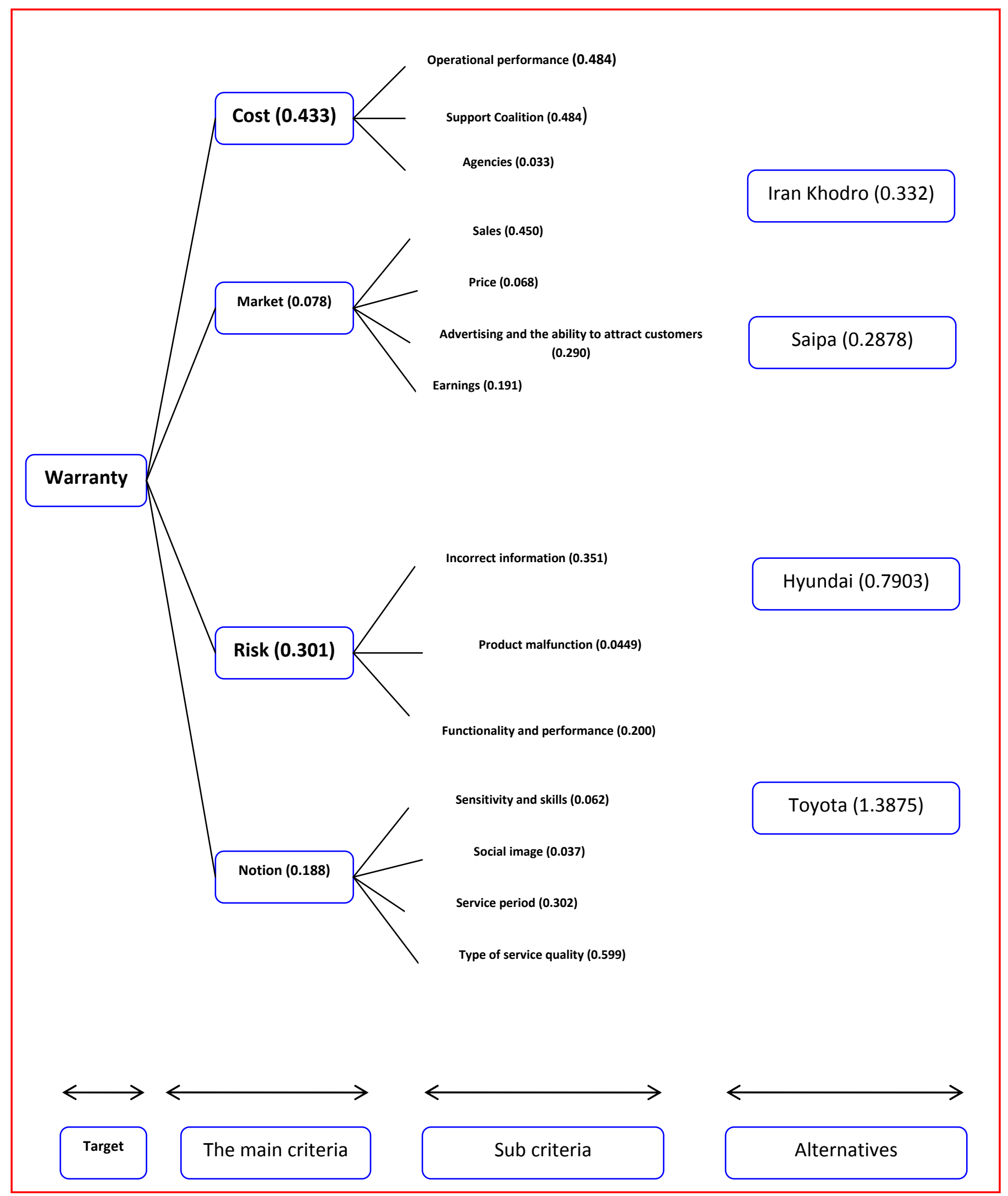

Fig. 1. Hierarchical structure of fuzzy AHP 
The following calculation results can be obtained by software bundle. As we can observe from the results of Table 1, Toyota is ranked first followed by Hyundai, Iran Khodro and Saipa comes in the last.

Table 1

Results of fuzzy AHP approach

\begin{tabular}{|c|c|c|c|c|c|c|}
\hline Criteria & Sub-criteria & $\begin{array}{l}\text { Iran } \\
\text { khodro }\end{array}$ & Saipa & Hyundai & Toyota & weights \\
\hline & Operational performance & 0.012 & 0.226 & 0.311 & 0.452 & 0.2095 \\
\hline \multirow[t]{4}{*}{ Cost } & Support Coalition & 0.276 & 0.264 & 0.185 & 0.276 & 0.2095 \\
\hline & agencies & 0.262 & 0.262 & 0.213 & 0.262 & 0.0142 \\
\hline & Sales & 0.096 & 0.137 & 0.312 & 0.455 & 0.0351 \\
\hline & price & 0.144 & 0.042 & 0.276 & 0.539 & 0.0053 \\
\hline \multirow[t]{3}{*}{ Market } & $\begin{array}{l}\text { Advertising and the ability to attract } \\
\text { customers }\end{array}$ & 0.266 & 0.266 & 0.201 & 0.266 & 0.0226 \\
\hline & Earnings & 0.346 & 0.131 & 0.177 & 0.346 & 0.0148 \\
\hline & Incorrect information & 0.267 & 0.267 & 0.2 & 0.267 & 0.1056 \\
\hline \multirow[t]{4}{*}{ Risk } & Product malfunction & 0.146 & 0.308 & 0.238 & 0.308 & 0.1351 \\
\hline & Functionality and performance & 0.022 & 0.206 & 0.289 & 0.483 & 0.0274 \\
\hline & Sensitivity and skills & 0.022 & 0.206 & 0.289 & 0.483 & 0.0116 \\
\hline & Social image & 0.266 & 0.266 & 0.201 & 0.266 & 0.0069 \\
\hline \multirow[t]{3}{*}{ Notion } & Service period & 0.266 & 0.266 & 0.201 & 0.266 & 0.0567 \\
\hline & Type of service quality & 0.266 & 0.266 & 0.201 & 0.266 & 0.1126 \\
\hline & Total results & 0.3332 & 0.2878 & 0.7903 & 1.3875 & \\
\hline
\end{tabular}

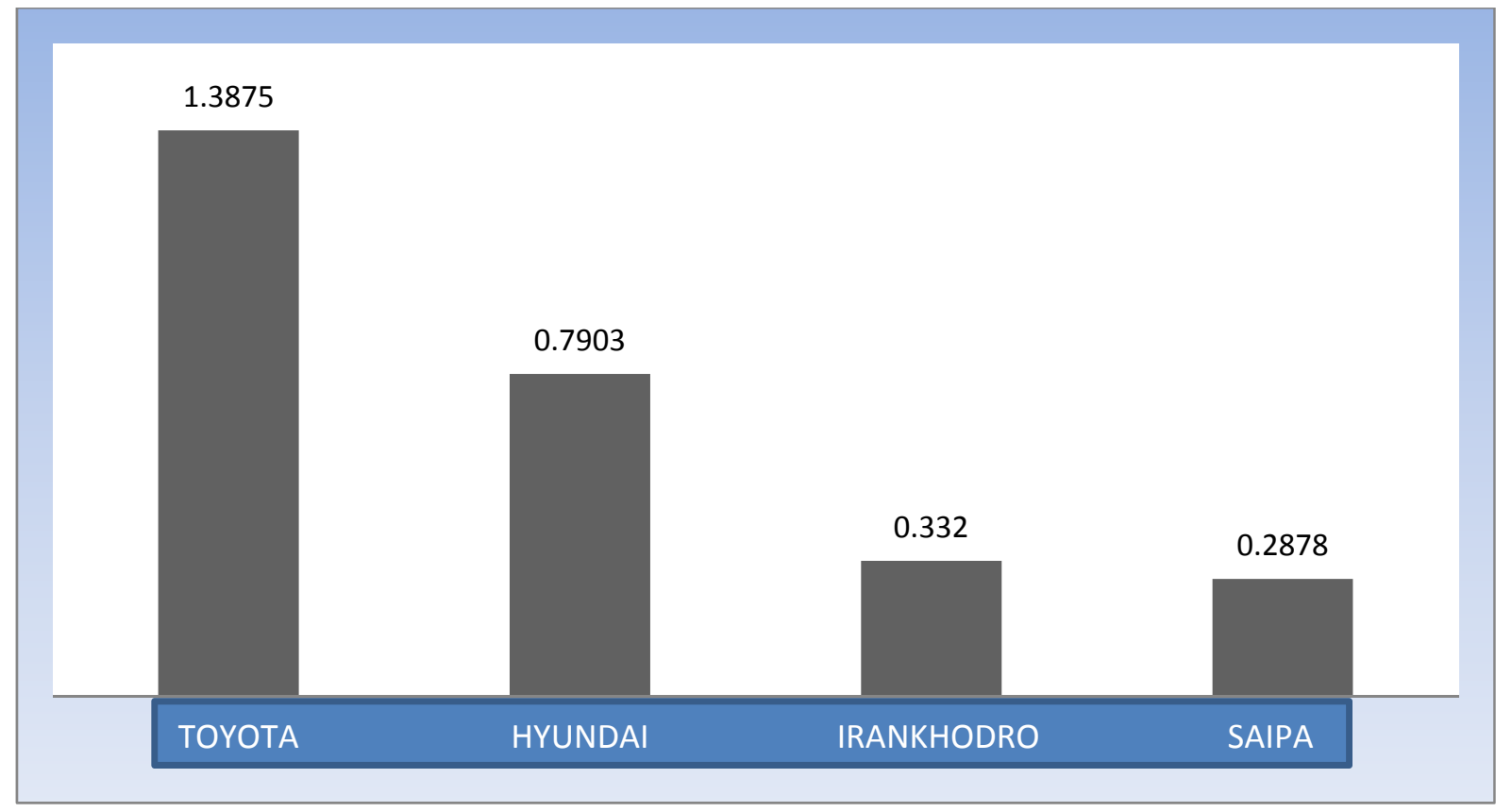

Fig. 2. Final results of comparing four auto producers

In summary, we can conclude that TOYOTA performed better warranty features in Iran, followed by HYUNDAI, IRANKHODRO and SAIPA. 


\section{Conclusion and discussion}

Lack of professional attention to broadband and absorbing the forces in this area, which is the results of less experience; have caused the reduction of quality customer service. Although much efforts have been made in this area and automakers have taken the necessary steps to provide the conducted training to broadband, agency staff still facing the problem of illiteracy. However, it is important to note that many representatives of the automotive after-sale services do their job well. Despite the fact that in Iran, there are many automakers but they have been unable to provide good after sale services. The proposed study of this paper has considered four criteria of cost, market, risk and notion and reported that cost played the most important factor followed by risk, notion and market. In terms of cost, operational performance and support coalition were the most important factors while product malfunction was the most important factor in risk component.

\section{References}

Blischke, W.R. (1990). Mathematical models for analysis of warranty policies. Mathematical Computational Modeling, 13, 1-16.

Blischke, W.R., \& Murthy, D.N.P. (1992). Product warranty management - I:A taxonomy for warranty policies. European Journal of Operational Research, 62, 127-148.

Christozov, D., Chukova, S., Mateev, P. (2009). On two type of warranties: Warranty of malfunctioning and warranty of misinforming, Asia-Pacific Journal of Operational Research, 26(3), 1-22.

Chukova, S., Dimitrov, B., Rykov, V.V. (1993). Warranty analysis. Journal of Soviet Mathematics, 67, 3486-3508.

Glickman, T. S., \& Berger, P. D. (1976). Optimal price and protection period decisions for a product under warranty. Management Science, 22, 1381-1389.

Iskandar, J., \& Murthy, B. P. (2009). DNP, A repair-replace strategy based on usage rate for items sold with a two-dimensional warranty. Reliability Engineering and System Safety, 94, 611-617.

Ives, B., \& Vitale, M.R. (1988). After the sale: Leveraging maintenance policy over a warranty period. Microelectronic Reliability, 34, 529-534.

Ives, B., \& Vitale, M. R. (1988). After the sale: Leveraging maintenance with information technology. MIS Quarterly, 12, 7-21.

Maronick, T. J. (2006). Consumer perceptions of extended warranties. Journal of Retailing and Consumer Services, 14(3), 224-231.

McGuire, E.P. (1980). Industrial Product Warranties: Policies and Practices. The Conference Board Inc, New York.

Mitra, A., \& Jayprakash, G.P. (1990). A multi-objective model for warranty estimation. European Journal of Operational Research, 45, 347-355.

Mitra, A., \& Jayprakash, G.P. (1997). Market share and warranty costs for renewable warranty programs. International Journal of Production Economics, 50, 155-168.

Murthy, D.N.P, \& Blischke, W.R. (1992). Product warranty management -II:An integrated framework for study. European Journal of Operational Research, 62, 261-281.

Murthy, D.N.P., \& Blischke, W.R. (1992). Product warranty management -III:A review of mathematical models. European Journal of Operational Research, 63, 1-34.

Murthy, D.N.P. , \& Djamaludin, I. (2002). New product warranty: A literature review. International Journal of Production Economics, 79, 231-260.

Murthy, D.N.P., \& Jack, N. (2003). Warranty and maintenance. Handbook of reliability engineering, 305-314.

Murthy, D.N.P., Solem , O., \& Roren, T. (2004). Production, manufacturing and logistics product warranty logistics: Issues and challenges. European Journal of Operational Research, 156, 110126. 
Petkova, V.T., Sander, P.C., \& Brombacher, A.C. (2000). The use of quality metrics in service centres. International Journal of Production Economics, 67, 27-36.

Polatoglu, H., \& Sahin, I. (1998). Theory and methodology probability distributions of cost, revenue and profit over a warranty cycle. European Journal of Operational Research, 108, 170-183

Park, M. and Pham, H. (2010). Altered quasi-renewal concepts for modeling reneable warranty costs with imperfect repairs. Mathematical and Computer Modeling, 52, 1435-1450

Richken, P.H., Chandramohan, J., Tapiero, C.S. (1989). Servicing, quality design and control. IIE Transactions, 21, 213- 220.

Scitovszky, T. (1945). Some consequences of the habit of judging quality by price. Review of Economic Studies, 12, 100-105.

Teng, J.T., \& Thompson, G.L. (1996). Optimal strategies for general price-quality decision models of new products with learning production costs. European Journal of Operational Research, 93, 476-489.

Thomas, M.U., \& Rao, S.S. (1999). Warranty economic decision model: A summary and some suggested directions for future research. Operation Research 47, 807- 820.

Wang, H., \& Pham, H. (2006). Reliability and optimal maintenance. Springer.

Wang, L., Chu, J., \& Wu, J. (2007). Selection of optimum maintenance strategies based on a fuzzy analytic hierarchy process. International Journal of Production Economics, 107, 151-163.

Wu, C.C., Lin, P.C., \& Chou, C.Y. (2006). Determination of price and warranty length for a normal lifetime distributed product. International Journal of Production Economics, 102, 95-107. 